\title{
A Study on NS1 Antigen Detection ELISA Assay in Comparison with RNA Detection by Reverse Transcription Polymerase Chain Reaction for the Early Diagnosis of Dengue
}

\author{
G. Sushma Rajya Lakshmi ${ }^{*}$, K. Nagamani ${ }^{1}$, K. Naga Soujanyai ${ }^{1}$, \\ Manisha Rani ${ }^{1}$, Sunitha Pakalapaty ${ }^{1}$ and Swathi Akula ${ }^{2}$ \\ ${ }^{1}$ Department of Microbiology, Gandhi Medical College, Secunderabad, Telangana India \\ ${ }^{2}$ Department of Microbiology, Kamineni Institute of Medical Sciences, \\ LB Nagar, Telangana, India \\ *Corresponding author
}

A B S T R A C T

\begin{tabular}{|l|}
\hline Ke y w or d s \\
$\begin{array}{l}\text { ELISA, Polymerase } \\
\text { chain reaction, } \\
\text { Acute phase. }\end{array}$ \\
\hline Article Info \\
\hline $\begin{array}{l}\text { Accepted: } \\
12 \text { October } 2017 \\
\text { Available Online: } \\
10 \text { December } 2017\end{array}$ \\
\hline
\end{tabular}

\section{Introduction}

Dengue fever (DF) is the fastest emerging arboviral infection spread by Aedes aegypti mosquitoes with major public health consequences for millions of people around the world, and in particular the South-East
Asia and Asia-Pacific Regions of the World Health Organization. The ecological disruption that occurred in the Southeast Asia and Pacific Regions during and following World War II, created ideal conditions for 
viral transmission and an increase of mosquito borne disease and it was in this setting that a global pandemic of Dengue began. The vast expansion of shipping and the development of port cities in the 18th and 19th centuries, led to the spread of Dengue virus to new geographic areas causing major epidemics. Other factors believed to cause increase in Dengue epidemics are population growth and urbanization, deterioration in water quality, suboptimal waste management, the lack of effective mosquito control, and human air and ship travel (George and Lum, 1997).

In India, the first epidemic of clinical Dengue-like illness was recorded in Madras (now Chennai) in 1780. Dengue virus was isolated at Calcutta (now Kolkata) in 1944 from serum samples of US soldiers (Sabin and Scelesinger, 1945).

In Tamil Nadu, the first major outbreak of Dengue was noticed in Vellore, South Arcot district in 1961 and the viral etiology was established later by the isolation of Dengue virus (Carey et al., 1964). The first virologically proved epidemic of DF in India occurred in Calcutta and eastern coast of India in 1963 - 1964. Subsequently, the whole country was involved with wide spread epidemics followed by endemic or hyper endemic prevalence of all four serotypes of Dengue virus.

Dengue viruses belong to the Flavivirus genus of the Flaviviridae family. Flaviviruses are enveloped, single-strand RNA viruses. The genomic RNA is approximately $11 \mathrm{~kb}$ in size and encodes three structural proteins: $\mathrm{C}$ (core protein), $\mathrm{M}$ (membrane protein), and $\mathrm{E}$ (envelope protein). The genomic RNA is translated to generate a large polyprotein precursor, which is cotranslationally processed by host cell- and virus-encoded proteases to yield the individual viral proteins.
The non-structural (NS) proteins are NS1, NS2a, NS2b, NS3, NS4a, NS4b, and NS5 (WHO, 2014). NS1 is a highly conserved glycoprotein that seems to be essential for virus viability but has no established biological activity. Unusually for a viral glycoprotein, NS1 is produced in both membrane-associated and secreted forms. Enzyme-linked immunosorbent assays (ELISA) directed against the NS1 antigen have demonstrated that this antigen is present at high concentrations in the sera of dengue virus-infected patients during the early clinical phase of the disease (White head et al., 2007; WHO, 2004).

Dengue virus infection is currently detected by means of several biological tests: virus isolation on mosquito cells (Srivastava et al., 2011), viral RNA detection by reverse transcription-PCR (RT-PCR) (Gurukumar et al., 2009; Sreevastava et al., 2011), or serological tests, such as immunoglobulin $\mathrm{M}$ (IgM) capture enzyme-linked immunosorbent assay (MAC-ELISA)

Primary infection is characterized by the absence of Dengue-specific IgG antibodies in the acute serum sample and presence of antidengue IgM, virus isolation, and/or viral RNA detection, followed by the presence of antiDengue IgG in convalescent serum samples. Secondary infection is characterized by detection of specific anti-Dengue IgG in the acute sample and the absence of anti-Dengue IgM, associated with a positive Reverse transcriptase Polymerase chain reaction (RTPCR)and/or virus isolation, followed by the presence of anti-Dengue IgM in convalescent serum samples

Till date diagnosis is mainly by dengue $\operatorname{IgM}$ capture ELISA even in tertiary care hospitals and Infectious Disease Surveillance Programme (IDSP) reference laboratories. But IgM appears only after 3-5 days of illness 
in primary infection and persist for 2-3 months, whereas in secondary infections it is not always positive and dengue $\operatorname{IgG}$ persists for many years. Anti-dengue IgG and IgM antibodies in human sera cross-react with other flaviviruses The detection of dengue specific secretary NS1 (non-structural protein 1), a highly conserved glycoprotein represents a new approach to the diagnosis of acute DV infection, in recent times.

NS1-highly specific marker for diagnosis of dengue from day 1 of the fever, no need of repeating the test for rising titers. It remains circulating in patient's blood for longer period than does viral RNA and is reported to be detectable even up to 14th day of illness. Although the most effective method to diagnose dengue in the acute phase of the illness recommended by the WHO is detection of DENV RNA, widespread use of dengue molecular diagnostics has been hampered by lack of validated tests and testing capability, perceptions that molecular diagnostics are cost prohibitive compared to immunoassays and lack of recommendations for their use.

Dengue IgM and IgG ELISA kits are widely used for diagnosis of dengue infection in routine laboratories. However, there are variations in detection limit during acute phase of the disease. After the onset of symptoms, it usually takes 4-5 and 1-14 days respectively for anti- DENV IgM and $\operatorname{IgG}$ antibodies to become detectable, depending on whether the patient has primary or secondary infection (Seokumi et al., 2010). Isolation of virus in cell culture or in infant mouse brain remains the gold standard for diagnosis of acute cases. However, it requires specialized laboratories and takes more than a week for the test to be completed, making it impractical in most situations. Detection of viral RNA by RT-PCR also allows early diagnosis during febrile phase. However, the procedure is cumbersome and the interpretation is difficult; moreover, the results are not immediate, making its routine use in clinical diagnostic laboratories difficult (Marlitenorio et al., 2010).

In such a state of affairs, there is need for rapid, sensitive and high throughput methods for detection of dengue virus in the early stages of the disease. In the present study, we evaluated two new diagnostic tools for acute dengue virus infection. An enzyme immunoassay for detecting dengue virus NS1 antigen in human serum; and a dengue virus specific Taq Man based real time RT-PCR for detection of all four serotypes using a single probe primer set targeted against the 3UTR.

Thus the present study was conducted to compare NS1 antigen detection by ELISA and nucleic acid detection by nested RT PCR for early diagnosis of Dengue virus infection in patients attending Gandhi hospital.

\section{Materials and Methods}

Approval of the Institute's ethical committee was obtained to carry out the study.

\section{Settings}

Study Place: Department of Microbiology, Gandhi Medical College, Secunderabad

Study design: Prospective Cross-sectional Descriptive study

Study period: 18 months (June 2014November 2015)

\section{Inclusion criteria}

The patients of all age groups and both the sexes, having temperature $>38.5^{\circ} \mathrm{C}$ for $>24 \mathrm{hr}$ and $<10$ days of illness who were clinically diagnosed as having Dengue fever admitted in 
Medical and Paediatric Wards of Gandhi Hospital

\section{Exclusion criteria}

Febrile patients with duration of illness $>10$ days

\section{Immuno compromised}

The following are the case definitions as per WHO classification, which were applied for the study.

Suspected clinical case of dengue fever is defined as acute febrile illness with 2 or more of the following: headache, retro orbital pain, myalgia, arthralgia, rash, haemorrhagic manifestations and leucopoenia.

Probable case of dengue is a case compatible with clinical description and with positive IgM antibody test in acute serum specimen.

Confirmed case of dengue fever is defined as a case compatible with clinical description and laboratory confirmed either by detection of nucleic acid detection in the serum or NS1 antigen detection by validated immunoassay or fourfold rise in IgM or IgG antibodies in paired samples collected in acute and convalescent stages.

\section{Materials}

From June 2014 to November 2015, 1026 clinically suspected dengue patients attending Gandhi Hospital serum samples were referred to Microbiology laboratory for Dengue diagnosis. Serum samples were screened for dengue NS1 antigen and IgM antibodies by ELISA (Group A).

Out of 1026 clinically suspected cases, a subset of 330 cases, who could be followed up and who gave consent were included in the
study(Group B), detailed clinical and epidemiological and laboratory data were recorded using structured proforma.

Out of 330 cases in Group B, serum samples from randomly selected 119 patients (Group C) were subjected to nested multiplex RT PCR for detection and serotyping of Dengue virus.

\section{Methods}

\section{Serology}

Serum samples from all 1026 clinically suspected dengue patients (Group A) were subjected to NS1 antigen detection and IgM antibodies detection by ELISA.

In addition from 330 patients (Group B), serum samples were subjected to $\mathrm{IgG}$ antibodies detection by ELISA.

\section{Dengue NS1 antigen detection was done by sandwich ELISA}

Dengue IgM antibody detection was done by MAC ELISA supplied by Division of Arbovirus diagnostics (National institute of Virology (NIV), Pune). Dengue IgG antibody detection was done by indirect ELISA (Novatech immunodiagnostica, $\mathrm{GmbH}$, Germany). All the tests were performed according to the manufacturer's instructions.

\section{Dengue viral RNA detection and serotyping}

From 119 patients (Group C), serum samples were subjected to multiplex nested reverse transcriptase PCR.

Molecular method by multiplex nested RT PCR RNA extraction was done by conventional method-Trizol-ChloroformIsopropyl Alcohol Method. 
cDNA conversion by using random hexamer primers

$40 \mu 1$ of extracted RNA was suspended into PCR tubes and heated for $97^{\circ} \mathrm{C}$ for 5 minutes in PCR machine and then removed and chilled on ice for 5 minutes.

\section{Amplification of target cDNA}

cDNA was subjected to two step nested PCR. In primary PCR, group specific primers D1 and D2 were used to amplify $511 \mathrm{bp}$. In secondary PCR, type specific primers TS1, TS2, TS3 and TS4 were used to detect the serotype.

The amplified PCR product was subjected to $2 \%$ agarose gel electrophoresis. The amplified bands were detected by gel doc system. Well characterised serum samples showing NS1 positivity and RT-PCR positivity were used as controls (Fig. 1).

\section{Results and Discussion}

During the period from June 2014 to November 2015, 1026 clinically suspected dengue patients serum samples (Group A) were subjected to NS1 antigen detection and IgM antibodies detection by ELISA. Among them $338(32.9 \%)$ were dengue probable cases (only IgM ELISA positives) and 140 $(13.6 \%)$ were dengue confirmed cases. (Either NS1 ELISA positives or RT PCR positives) (Table 1).

In the year 2014 from July to November, 13.5 $\%$ of the 228 clinically suspected cases were diagnosed as probable cases and $30.2 \%$ were confirmed cases. In contrast to the period from July 2015 to November 2015, 34.8\% of 691 clinically suspected cases were diagnosed as probable cases and $14.6 \%$ as confirmed cases, this difference was found to be statistically significant with $\mathrm{p}$ value $<0.0001$
(Table 1). In 2014 as well as 2015, maximum number of cases was reported in September month. Out of 1026 cases received, number of Clinically suspected dengue cases and serological positives(by NS1 or IgM ELISA) showed slight difference in the month of September when two years were compared. In the year 2014 September month had 67 clinically suspected dengue cases out of which 26 cases were found to be serological positives while in 2015 there were 191 clinically suspected cases out of which 111 cases were serological positives.

This variation was found to be statistically significant with $\mathrm{p}$ value $=0.00098$. Thus there is increase in seropositivity in the month of September for the years 2014 and 2015 from $38.8 \%$ in 2014 to $58.1 \%$ in 2015 .

Thus the incidence was higher in 2015 with 191 clinically suspected cases, 77 probable cases and 35 confirmed cases in comparison with 2014 which had 67 clinically suspected cases, 16 probable cases and 10 confirmed cases.

Serological profile of clinically suspected cases included in the study group $(n=330)$

In the present study, out of 330 samples, NS1 antigen was positive in 75 cases (22.7\%), IgM ELISA positive in 118 cases $(35.7 \%)$ and IgG was positive in 281 cases $((85.1 \%)$. Though the percentage of $\operatorname{IgG}$ positive samples was high, they were not considered due to their persistence lifelong and also as paired sera was not collected from the patients for confirmation of Dengue infection (Table 2).

Comparison of NS1 antigen and RNA detection with the day of sample collection post fever onset $(n=72)$ (Table 3)

In the present study, both NS1 antigen detection and RNA detection was highest on 
day 3 of illness. NS1 antigen was detected from day 2 to day 10 of illness, in case of RT PCR was detected from day 2 to day 8 of illness (Table 3).

Among 119 cases (group C), in 71 NS1 Ag positive cases, RT PCR positivity was 39.4\%.In 103 IgM positive cases, RT- PCR positivity was $20.38 \%$ (Table 4 ).

Thus sensitivity of NS1 Ag was $97.26 \%$ and sensitivity of multiplex RT PCR was $40.27 \%$, while specificity for both was $100 \%$ (Table 5 ). The positive and negative predictive value were 100 and $97.91 \%$ for NS1 Ag, in case of RT-PCR, positive and negative predictive values were 100 and $52.22 \%$ respectively.
$\%$ Concordance $($ Agreement $)=$ No of samples positive by both tests + no of samples negative by both tests $\mathrm{x} 100$

\section{Total no of samples}

Concordance between NS1 antigen detection by ELISA and Multiplex RT PCR was found to be maximum on day 5 of illness and minimum on day 2 of illness.

During the period from June 2014 to November 2015 in Telangana, a total of 1026 clinically suspected dengue patients attending Gandhi Hospital serum samples were referred to Microbiology laboratory for diagnosis of dengue.

Table.1 Comparison of Dengue cases prevalent during the period July to

November in 2014 and 2015

\begin{tabular}{|l|c|c|}
\hline & $\begin{array}{c}\mathbf{2 0 1 4} \\
\text { (July to November) } \\
(\mathbf{n = 2 2 8})\end{array}$ & $\begin{array}{c}\mathbf{2 0 1 5} \\
\text { (July to November) } \\
(\mathbf{n = 6 9 1 )}\end{array}$ \\
\hline Total Suspected dengue cases & 228 & 691 \\
\hline $\begin{array}{l}\text { Probable dengue cases((Proportion of total } \\
\text { cases) }\end{array}$ & $31(13.5 \%)$ & $241(34.8 \%)$ \\
\hline Confirmed dengue cases & $69(30.2 \%)$ & $101(14.6 \%)$ \\
\hline
\end{tabular}

Table.2 Serological profile of clinically suspected cases $(n=330)$

\begin{tabular}{|l|c|}
\hline \multicolumn{1}{|c|}{ Parameter } & $\begin{array}{c}\text { No of cases positive by respective } \\
\text { ELISAs }\end{array}$ \\
\hline NS1 Ag only & 8 \\
\hline $\mathrm{NS} 1 \mathrm{Ag}+\mathrm{IgM}$ & 23 \\
\hline $\mathrm{NS} 1 \mathrm{Ag}+\mathrm{IgG}$ & 8 \\
\hline $\mathrm{NS} 1 \mathrm{Ag}+\mathrm{IgM}+\mathrm{IgG}$ & 36 \\
\hline IgM + IgG & 41 \\
\hline IgM only & 18 \\
\hline IgG only & 196 \\
\hline Total & 330 \\
\hline
\end{tabular}


Table.3 Comparison of NS1 antigen and RNA detection with the day of sample collection post fever onset $(n=72)$

\begin{tabular}{|c|c|c|c|}
\hline $\begin{array}{c}\text { Sample collection } \\
\text { post fever onset } \\
\text { (Days) }\end{array}$ & $\begin{array}{c}\text { No of Samples } \\
\text { positive by NS1 Ag }\end{array}$ & $\begin{array}{c}\text { No of samples } \\
\text { positive by multiplex } \\
\text { RT PCR }\end{array}$ & $\begin{array}{c}\text { Total number of } \\
\text { confirmed } \\
\text { dengue } \\
\text { cases(n=72) }\end{array}$ \\
\hline 1 & 0 & 0 & 0 \\
\hline 2 & 6 & 1 & 6 \\
\hline 3 & 16 & 10 & 16 \\
\hline 4 & 12 & 6 & 12 \\
\hline 5 & 12 & 8 & 13 \\
\hline 6 & 7 & 2 & 7 \\
\hline 7 & 5 & 1 & 7 \\
\hline 8 & 7 & 1 & 3 \\
\hline 9 & 3 & 0 & 3 \\
\hline 10 & 3 & 0 & 72 \\
\hline Total & 71 & 29 & \\
\hline
\end{tabular}

Table.4 Relationship between dengue serology parameters and multiplex RT PCR

\begin{tabular}{|c|c|c|}
\hline Positive by & $\begin{array}{c}\text { No of cases screened for } \\
\text { PCR }\end{array}$ & $\begin{array}{c}\text { No of positive cases detected } \\
\text { by PCR }\end{array}$ \\
\hline NS1Ag only & 16 & $8(50 \%)$ \\
\hline NS1Ag + IgM & 55 & $20(36.36 \%)$ \\
\hline IgM only & 48 & $1(2.08 \%)$ \\
\hline Total & 119 & $29(24.3 \%)$ \\
\hline
\end{tabular}

Table.5 Efficacy of the NS1 antigen and RT- PCR assays used in the diagnosis of dengue fever

\begin{tabular}{|c|c|c|c|c|}
\hline Test & Sensitivity & Specificity & $\begin{array}{c}\text { Positive } \\
\text { predictive } \\
\text { value }\end{array}$ & $\begin{array}{c}\text { Negative } \\
\text { predictive } \\
\text { value }\end{array}$ \\
\hline NS1 Ag & $97.26 \%$ & $100 \%$ & $100 \%$ & $97.91 \%$ \\
\hline $\begin{array}{c}\text { Multiplex nested } \\
\text { RT- PCR (RT } \\
\text { PCR) }\end{array}$ & $40.27 \%$ & $100 \%$ & $100 \%$ & $52.22 \%$ \\
\hline
\end{tabular}

Table.6 Comparison of NS1antigen detection and Multiplex RTPCR

\begin{tabular}{|l|l|l|l|l|l|}
\hline $\begin{array}{l}\text { NS1 antigen } \\
\text { detection }\end{array}$ & $\begin{array}{l}\text { RT PCR } \\
\text { positive }\end{array}$ & $\begin{array}{l}\text { RT PCR } \\
\text { negative }\end{array}$ & Total & Concordance\% & Discordance\% \\
\hline Positive & 28 & 43 & 71 & $63.02 \%$ & $36.98 \%$ \\
\hline Negative & 1 & 47 & 48 & & \\
\hline Total & 29 & 90 & 119 & & \\
\hline
\end{tabular}


Table.7 Concordance between dengue NS1 antigen detection ELISA and multiplex RT PCR on different day of illness

\begin{tabular}{|c|c|c|}
\hline Day of illness & $\begin{array}{c}\text { Total no of samples for } \\
\text { which tests were done }\end{array}$ & Concordance (\%) \\
\hline 1 & - & - \\
\hline 2 & 6 & 16.6 \\
\hline 3 & 17 & 64.7 \\
\hline 4 & 15 & 60 \\
\hline 5 & 17 & 76.47 \\
\hline 6 & 21 & 76.1 \\
\hline 7 & 15 & 73.3 \\
\hline 8 & 12 & 50 \\
\hline 9 & 10 & 60 \\
\hline 10 & 6 & 50 \\
\hline
\end{tabular}

Fig.1 Gel documentation of RT PCR analysis of dengue virus serotype specific amplicons

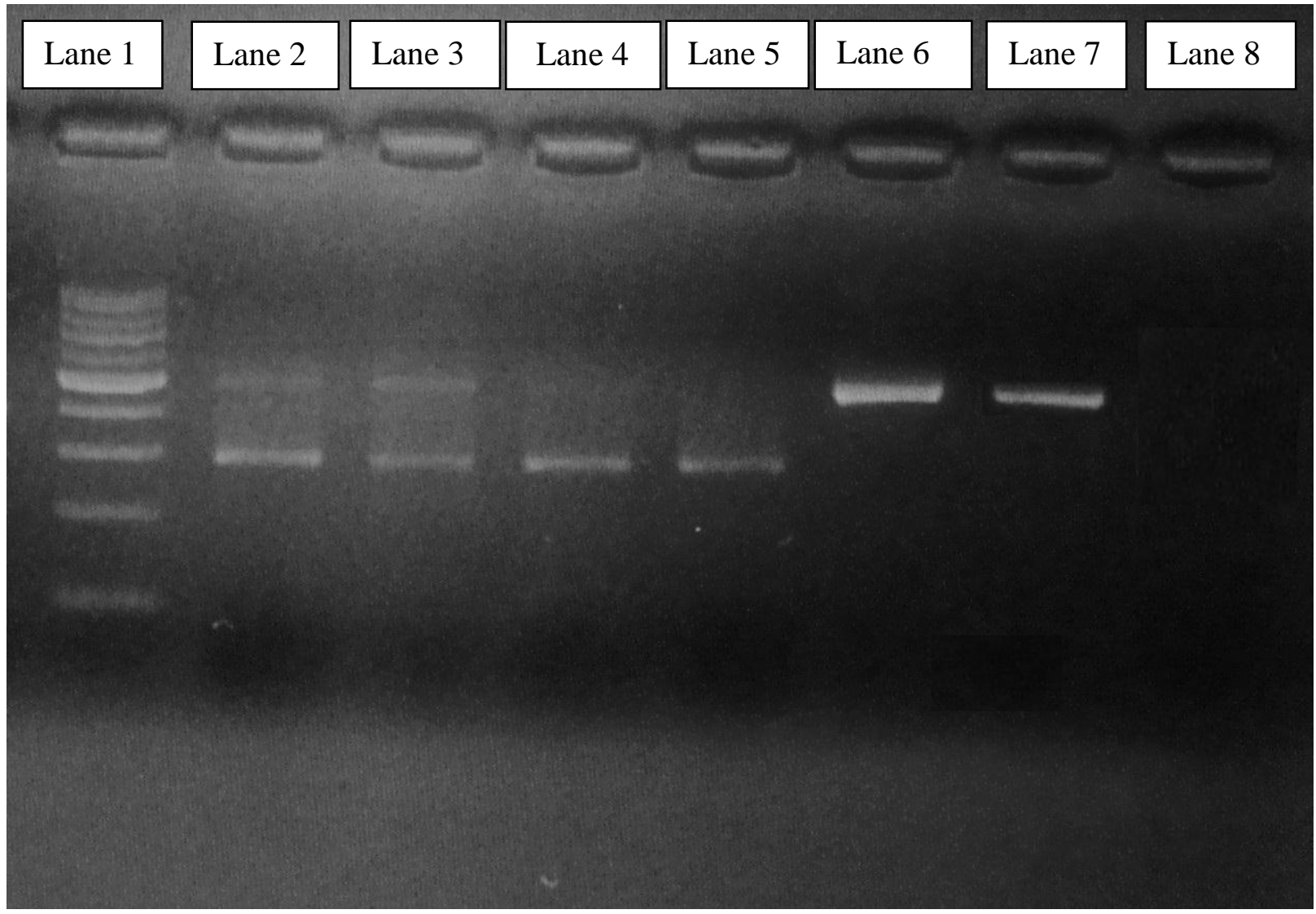

Lane 1-Ladder,

Lane 2-DENV 3 positive control (289bp),

Lane 3, 4 and 5 -DENV 3 (samples),

Lane 6-DENV 1 positive control (482bp),

Lane 7-DENV 1 (sample),

Lane 8-negative control 
The incidence of dengue during both the years was observed more during the period July to November with peak incidence reported from August to October which is the breeding season for the mosquitos similar to the previous findings (Nidhi et al., 2012; Khan et al., 2010). In the year 2014 from July to November, $13.5 \%$ of the 228 clinically suspected cases were diagnosed as probable cases and $30.2 \%$ were confirmed cases. In contrast to the period from July 2015 to November 2015, 34.8\% of 691 clinically suspected cases were diagnosed as probable cases and $14.6 \%$ as confirmed cases, this difference was found to be statistically significant with $\mathrm{p}$ value $<0.0001$. This may be due to heavy load of migrating population from dengue endemic areas, lack of effective vector control measures, due to ecological and climatic factors. A similar change in the IgM positivity was observed in previous study in Lucknow, who reported $54.5 \%$ IgM positivity in $2008,51.9 \%$ positivity in 2009 and $64.9 \%$ positivity in 2010 but the increase was not related changes in environmental factors like rainfall, temperature and humidity (Nidhi et al., 2012).. The IgM positive cases were reported all the year round similar to the other studies in Hongkong (Chuang et al., 2008). Some other similar findings reported in Uttara Pradesh and in Pakistan (Tripathi et al., 2008; Khan et al., 2010). This trend may be due to the hyperendemicity of the virus,co circulation of all four serotypes and may be because the vector has adapted to extremes of warm and cold weather resulting in Dengue cases round the year.

In the present study, we looked into the worth of dengue virus NS1 antigen detection and dengue group specific real time RT-PCR for diagnosing dengue cases in acute phase of illness.

In the present study, NS1 antigen only was positive in $2.12 \%$, IgM only positive in $6 \%$,
IgG only in $59.3 \%$ similar to other earlier studies (Swathi and Nagamani, 2014). Whereas some other findings reported $29.6 \%$ positive by NS 1 antigen only,53.3\% by IgM only and $2.8 \%$ by IgG only (Kulakarni et al., 2011).

In the present study, positive detection rate for NS1 Ag ELISA was 59.6\% and for multiplex RT PCR was $24.3 \%$ respectively. These studies were similar to other previous findings (Swathi and Nagamani, 2004; Nishath Hussain and Shoba, 2014). Some earlier reports stated that multiplex RT-PCR showed $34 \%$ and $32.7 \%$ for positive detection rate for NS1 Ag ELISA (Nishath Hussain and Shoba, 2014).

The present study revealed that sensitivity of RT PCR was $40.27 \%$ and these results agreement with previous report (Aziz et al., 2002). But some studies showed low sensitivity $5.3 \%$ respectively (Das et al., 2005; Gupta et al., 2006).

From our results, we found that, the Sensitivity of NS1 Ag was much higher with 97.26\% when compared with the sensitivity of multiplex RT PCR which was $40.27 \%$, while specificity for both was $100 \%$. The results showed that concordance between NS1 antigen detection by ELISA and Multiplex RT PCR was found to be $63.02 \%$. Concordance between NS1 antigen detection by ELISA and Multiplex RT PCR was found to be maximum on day 5 of illness and minimum on day 2 of illness (Table 6).

It is acknowledged that the management of dengue fever is conservative; nevertheless, strict monitoring of clinical condition and hematological parameters is required to prevent complications, which makes early diagnosis pertinent. Early diagnosis is also vital for exclusion, as dengue fever in most of the cases is clinically indistinguishable from 
other febrile illnesses prevailing in "dengue season". Furthermore, early diagnosis plays a crucial role in forecasting a timely warning of an epidemic and in undertaking effective vector control measures.

Positive detection rate for NS1 Ag ELISA was $59.6 \%$ and for multiplex RT PCR was $24.3 \%$ similar to other findings (Swathi and Nagamani, 2004; Shrivastav et al., 2011). Whereas some other studies reported $34 \%$ multiplex RT PCR positive detection rate and $32.7 \%$ positive detection rate for NS1 Ag ELISA (Chuang et al., 2008; Nishat Hussain et al., 2014).

In the present study, Sensitivity of RT-PCR was $40.27 \%$ similar to previous reports (Aziz et al., 2002; Swathi \& Nagamani, 2014). While some earlies studies reported low sensitivity 5.3\% (Das et al., 2005). From these studies concluded that both the methods have useful for the early detection of Dengue virus in acute phase of infection.

With the expansion of the geographic range of dengue fever and the increasing number and severity of reported cases, the use of NS1 antigen detection and real time RT-PCR could allow clinical diagnostic laboratories to identify dengue virus infections early enough to adjust patient management, reducing the time between detection of the first cases, and the notification of public health authorities, including vector control teams. To conclude, NS1 antigen detection, and dengue group specific real time RT-PCR are valuable techniques for the rapid and early biological diagnosis of dengue.

\section{Acknowledgement}

The authors are thankful to the faculty, technicians and to non-teaching staff of Department of Microbiology, Gandhi Medical College, Secunderabad, Telangana, India, for providing facilities to carry out the research work. We are also thankful to Medicine, Paediatric and SPM departments for their support to carry out this work.

\section{References}

Aziz, M.M., KN Hasan, K.N., Hasanat, M.A., Siddiqui, M.A., M Salimullah, M., Chowdhury, A.K., Moslehuddin, A., Alam, M.N. and Hassan, M.S. 2002. Predominance of the den-3 genotype during the recent dengue outbreak in Bangladesh. South East Asian J Trop Med Public Health., 33(1):42-48.

Carey, D.E., Myers, R.M.and Reuben, R. 1964. Dengue types 1 and 4 viruses in wild-caught mosquitoes in south India. Science. 143: 131-132.

Chuang, V.W, Wong, T.Y., Leung, Y.H, Ma, E.S. and Law, Y.L, 2008. Review of dengue fever cases in Hong Kong during 1998 to 2005. Hong Kong Med J., 14:170-177

Dash, P.K., Saxena, P., Abhyankar, A., Bhargava, R. and Jana, A.M. 2005. Emergence of dengue virus type-3 in northern India. Southeast Asian J. Trop. Med. Public Health., 36: 370-377.

George, R. and Lum L.C.S, 1997. Clinical spectrum of dengue infection. In: Gubler DJ, Kuno G (Eds). Dengue and dengue hemorrhagic fever. London: CAB International. Pp. 89-113.

Gupta, E., Dar L., Kapoor, G. And Broor, S. 2006. The changing epidemiology of dengue in Delhi, India. Virology Journal. 3(1): 92-96.

Gurukumar, K.R., Priyadarshini, D., Patil, J.A., Bhagat Singh, A. and Shah, P.S, et al., 2009. Development of real time PCR for detection and quantitation of dengue viruses. Virol J., 6: 10.

Khan, E., Kisat, M., Khan, N., Nasir, A., Ayub, S. and Hasan, R. 2010. Demographic and clinical features of 
dengue fever in Pakistan from 20032007: a retrospective cross-sectional study.PLoS One., 5(9): 22-30.

Kulkarni, R.D., Patil, S.S., Ajantha,G.S., Upadhya, A.K., Kalabhavi, A.S., Shubhada, R.M., Shetty, P.C. and Jai, P.A.. 2011. Association of platelet count and serological markers of dengue infection- importance of NS1 antigen. Indian J. Med. Microbiol., 29(4): $359-62$

MarliTenório, C., Ana Maria S., Carlos, A.A. Brito, E., J.M., Nascimento, J.M., Maria, C. and Magalhães, F. 2007. Characterization of a Dengue Patient Cohort in Recife, Brazil. Am J Trop Med Hyg., 77 (6): 1128-1134.

Nishat Hussain, A. and Shobha Broor, J. 2014. Comparison of NS1 antigen detection ELISA, real time RT-PCR and virus isolation for rapid diagnosis of dengue infection in acute phase., 51: 194-199

Sabin, A.B. and Schlesinger, M.C. 1945. Production of immunity to dengue 4 . with virus modified by propagation RNA in mice. Science. 101: 640-2.

SeokMui, W. and Shamala Devi， S. 2010. Early Diagnosis of Dengue Infection Using a Commercial Dengue Duo Rapid Test Kit for the Detection of NS1, IGM, and IG g. Ame. J Trop Med Hyg., 83(3): 690-695.
Srivastava, A., Dash, P.K, Tripathi, N.K., Sahni, A.K., Gopalan, N. And Lakshmana Rao, P.V. 2011. Evaluation of a commercial dengue NS1 enzymelinked immunosorbent assay for early diagnosis of dengue infection. Indian $J$ Med Microbiol., 29 (1): 51-5.

Swathi, A. and Nagamani, K. 2014. Serological and virological profile of dengue fever in a tertiary care hospital, southern part of Hyderabad, during 2011-12. Volume 1st Issue 4th, International Journal of Microbiology., 1(4): 6-10.

Tripathi, P., Kumar, R., Tripathi, S., Tambe, J.J. and Venkatesh, V. 2008 Descriptive epidemiology of dengue transmission in Uttar Pradesh. Indian Pediatr., 45:315-318.

Whitehead, S. S, Blaney, J.E., Durbin, A.P.and Murphy, B.R. 2007.Prospects for a dengue virus vaccine. Nat Rev Microbiol., 5: 51828

World Health Organization (2014). Dengue and severe dengue. Fact sheet no. 117, March 2014. Geneva: WHO, http://www.who.int/mediacentre/factshe ets/fs117/en/ - accessed 16 March 2014). Molecular diagnostics made simple. 2014. www.optigene.co.ukAccessed on 13th Ocober 2014.

\section{How to cite this article:}

Sushma Rajya Lakshmi, G., K. Nagamani, K. Naga Soujanyai, Manisha Rani, Sunitha Pakalapaty and Swathi Akula. 2017. A Study on NS1 Antigen Detection ELISA Assay in Comparison with RNA Detection by Reverse Transcription Polymerase Chain Reaction for the Early Diagnosis of Dengue. Int.J.Curr.Microbiol.App.Sci. 6(12): 1586-1596. doi: https://doi.org/10.20546/ijcmas.2017.612.178 